\title{
The role of the Sahara Low in summertime Sahel rainfall variability and change in the CMIP3 models.
}

M. Biasutti ${ }^{1}$ A. H. Sobel ${ }^{2}$, and Suzana J. Camargo ${ }^{1}$

Received — ; accepted —_

Submitted to Journal of Climate,

Corresponding author address: Michela Biasutti, Lamont-Doherty Earth Observatory of Columbia University - Oceanography

61 Route 9W - PO Box 1000, Palisades, NY 10968-8000.

E-mail: biasutti@ldeo.columbia.edu

Short title:

\footnotetext{
${ }^{1}$ Lamont-Doherty Earth Observatory of Columbia University, Palisades, NY.

${ }^{2}$ Columbia University, New York, NY.
} 


\begin{abstract}
Projections for $21^{\text {st }}$ century changes in summertime Sahel precipitation differ greatly across models in the CMIP3 dataset, and cannot be explained solely in terms of discrepancies in the projected anomalies in global SST.

This study shows that an index describing the low-level circulation in the north Atlantic-African region, namely the strength of the low-level Saharan Low, correlates with Sahel rainfall in all models and at the timescales of both interannual/interdecadal natural variability, and of the forced centennial trend.

An analysis of Sahel interannual variability provides evidence that variations in the Sahara Low can be a cause, not just a consequence, of variations in Sahel rainfall and suggests that a better understanding of the sources of model discrepancy in Sahel rainfall predictions might be gained from an analysis of the mechanisms influencing changes in the Sahara Low.
\end{abstract}




\section{Introduction}

As a global mean temperature increase in response to increasing atmospheric greenhouse gases becomes more certain (Meehl et al., 2007b), new challenges emerge: to reach similar certainty regarding the response of other climatic variables, first and foremost of precipitation, and to describe the climate response at the regional level.

Important disagreements remain with regards to the regional precipitation response to global warming. Different numerical climate models give very different answers (Neelin et al., 2006; Christensen et al., 2007). The African monsoon is a case in point (Cook, 2008). The models of the third Coupled Model Intercomparison Project (CMIP3) used for the fourth assessment report (AR4) of the Intergovernmental Panel on Climate Change (IPCC) disagree on the sign of future anomalies in the Sahel (see Figure 1 and Biasutti and Giannini, 2006; Cook and Vizy, 2006; Lau et al., 2005). Although the median difference between the last 25 years of the $21^{\text {st }}$ and of the $20^{\text {th }}$ century (21C-20C, Figure 1, bottom) is at most a few percentage points of the annual precipitation, the wettest and driest models predict August changes of about $8 \%$ of total annual rainfall - a change of about 30\% from current August values. If one of the extreme projections were to be realized, they would greatly affect the environment and the livelihood of the people living in the Sahel. Therefore, even though the median anomalies are small, the simulations of Sahel climate change require close scrutiny.

Plausible explanations have been proposed for projections of both a worsening drought and a substantial increase in rainfall. The mechanisms that control changes in Sahel rainfall variability at the interannual and interdecadal time scale can be used to interpret the global warming signal: on one hand Hoerling et al. (2006) point to the reversal in the anomalous cross-equatorial Atlantic sea surface temperature (SST) gradient as the global warming signal intensifies as the cause of a predicted recovery in Sahel rainfall. On the other hand, Held et al. (2005) show a very robust drying in 
the Sahel even in the presence of a reversal of the Atlantic gradient, and attribute it to either a uniform warming or a warming of the Indian ocean (Held et al., 2005; Bader and Latif, 2003): a warmer ocean would produce a warmer troposphere in the entire tropical band and more stable conditions over Africa, leading to a reduction of rainfall over the Sahel (Giannini et al., 2008; Herceg et al., 2007).

Biasutti et al. (2008) look at pre-industrial, $20^{\text {th }}$ and $21^{\text {st }}$ century simulations in the CMIP3 coupled models and explore whether the same paths of SST influence on Sahel rainfall that are responsible for its interannual and interdecadal variability are relevant for the long-term, forced change. In that study, a linear statistical model that predicts variations in Sahel rainfall from variations in the tropical Atlantic meridional gradient of SST and in the tropical Indo-Pacific SST is trained on the simulations of natural variability during pre-industrial times and shown to be skillful at predicting Sahel natural variability in both the $20^{\text {th }}$ and $21^{\text {st }}$ centuries in a majority of models. When the same linear model is applied to the forced component of Sahel variability, it is successful in reproducing the centennial trend in rainfall during the $20^{\text {th }}$ century, but not - for many models - during the $21^{\text {st }}$. As a summary of the results of Biasutti et al. (2008), we show here (Figure 2) the simulated trends in the tropical Atlantic gradient and in Indo-Pacific SST, plotted against the corresponding trends in Sahel rainfall. In both cases, there is no correspondence between the SST and the rainfall trends across the CMIP3 dataset. Biasutti et al. (2008) conclude that either non-linearity and details of the SST anomaly pattern are of paramount importance in deciding the sign of future rainfall anomalies or, more likely, other forcings besides SST are also playing a role.

Another approach for explaining future trends in the Sahel involves the mechanism responsible for the seasonal development of the "elementary" monsoon (Webster, 1987). According to this argument, an amplification of the land-sea thermal contrast (which is expected under global warming: Houghton et al., 1995; Sutton et al., 2007) will deepen 
the thermal Low over the Sahara, amplify the monsoon circulation, and bring more moisture, creating positive rainfall anomalies inland. A sensitivity experiment (Haarsma et al., 2005) shows that this mechanism applies to the NCAR model, and can therefore explain that model's projection of a wetter Sahel in the future. We have plotted the Sahel rainfall trend against two relevant measures of the $21^{\text {st }}$ century trend in land-sea thermal contrast (Figure 3): the gradient in surface equivalent potential temperature between the Sahara and the southern tropical Atlantic ocean (Eltahir and Gong, 1996; Emanuel, 1995) and the difference in surface temperature between the Sahara and the Tropics (e.g., Haarsma et al., 2005). The expected relationship between stronger land-sea thermal contrast and stronger monsoon rainfall does not hold. Not only do all models simulate an enhanced land-sea contrast while simulating both positive and negative rainfall trend, but the GFDL models simulate the strongest thermal contrast (at least by one measure), while simulating the strongest drying in the Sahel.

In summary, inter-models variations in the trends of either SST or land-sea thermal contrast cannot straightforwardly explain inter-model variations in Sahel rainfall trends. In trying to make sense of how disparate Sahel rainfall projections come about, this study examines the circulation changes that are linked to local rainfall changes. In the next section, we briefly introduce the datasets and describe our methods. In section 3 we present the trends in Sahara geopotential, an index of local circulation changes, and suggest that changes in the intensity of the Sahara Low might be a good predictor for changes in Sahel rainfall. In section 4 we look at the Sahara/Sahel relationship at interannual time-scales to make the point that independent variability in the Sahara can be a source of variability in the Sahel. In section 5 we discuss the implications of our results for the question of how to interpret different projections of climate change in the Sahel and offer our conclusions. 


\section{The Data Sets}

To compare model results to observations, we take advantage of the following datasets: for precipitation we use the gridded product $\left(3.75^{\circ} \times 2.5^{\circ} ; 1900\right.$ to 1996$)$ of the Climate Research Unit at the University of East Anglia (Hulme, 1992); for sea level pressure we use the Hadley Center product (available on a $5^{\circ} \times 5^{\circ}$ grid from 1871 to 1998 ; Allan and Ansell, 2006); for winds and geopotential height, we use the NCEP-NCAR reanalysis $\left(2.5^{\circ} \times 2.5^{\circ}\right.$, starting in 1949 ; Kalnay et al., 1996); the observed Niño 3.4 index (encompassing the area $120^{\circ} \mathrm{W}-170^{\circ} \mathrm{W}$ and $5^{\circ} \mathrm{S}-5^{\circ} \mathrm{N}$ ) is taken from Kaplan et al. (1998).

In this study we focus on the CMIP3 simulations of the $20^{\text {th }}$ century $(20 \mathrm{c} 3 \mathrm{~m}$ integrations in the dataset, hereafter $20 \mathrm{C}$ ) and on one scenario for the $21^{\text {st }}$ century (the first 100 years of the sresa1b integrations, hereafter 21C) by 24 coupled models (one single run per model). The $20 \mathrm{C}$ runs are forced by the historical anthropogenic emissions of greenhouse gases and sulfate aerosols and (for a subset of the models) by other anthropogenic and natural forcings. The $21 \mathrm{C}$ simulations assume a middle-of-the-road increase of greenhouse gases that stabilizes at 700ppm, and sulphate aerosols emissions increasing up to 2020 and decreasing afterwards. We will focus on the difference between the last twenty-five years of the $21^{\text {st }}$ century and those of the $20^{\text {th }}$ century (hereafter referred to as the $21 \mathrm{C}-20 \mathrm{C}$ difference), the linear trend over the $21^{\text {st }}$ century in the $21 \mathrm{C}$ simulations (or simply, the trend), and the variability at time scales shorter than the trend, calculated by linearly detrending the first 100 years of the $21 \mathrm{C}$ simulation (for brevity, interannual variability).

A full description of the CMIP3 integrations ${ }^{1}$ and a comprehensive assessment of

\footnotetext{
${ }^{1}$ These are made available to the community by the Program for Climate Model Diagnosis and Intercomparison (PCMDI) through their web-site
} 
the models can be found in Meehl et al. (2007a); Gleckler et al. (2008); Reichler and $\operatorname{Kim}(2008)$.

The performance of the CMIP3 dataset in simulating African climatology and variability has been described in previous studies (Cook and Vizy, 2006; Biasutti et al., 2008; Lau et al., 2005) and will not be evaluated in detail here. While biases of individual models are substantial in the representation of both the climatology and the variability, all models capture the basic pattern of the climatological rainfall progression in North Africa - although the annual cycle is not as peaked as the observed (See Figure 1, top, and, for more detail, Biasutti et al., 2008) — and most models capture, in a broad sense, the observed relationship between Sahel summer rainfall and tropical SST (the Atlantic SST gradient and, less consistently, the Indo-Pacific SST: Biasutti et al., 2008; Lau et al., 2005). Moreover, most models produce a dry Sahel at the end of the $20^{\text {th }}$ century (compared to the pre-industrial climate), in agreement with observations (Biasutti and Giannini, 2006).

Our intention in this study is both to shed some light on the mechanisms that can cause a long-term change in Sahel rainfall and to offer some suggestions as to why different models project different changes in this region. To understand the climate dynamics involved, we will turn to the mean or median of the CMIP3 models, which has been shown to be more accurate than any single model (Gleckler et al., 2008). To provide a sense of the range of results simulated, we single out (among the 24 models used for this study), four models with extreme Sahel rainfall anomalies: two that produce a dryer Sahel in 21C (the GFDL CM2.0 and CM2.1, which will be referred to as "dry" models) and two that produce a wetter Sahel (MIROC MEDRES and NCAR

(www-pcmdi.llnl.gov/ipcc/model_documentation/ipcc_model_documentation.php), where a full description of the models can be found. 
CCSM3, "wet" models).

The simulations of the GFDL models were analyzed by Held et al. (2005) in detail and are of particular interest because on one hand they provide very realistic simulations of the present global mean climate (Reichler and Kim, 2008) and of the $20^{\text {th }}$ century Sahel variability (capturing both the timing of the drought and its intensity) and on the other hand are outliers in their projections for large $21^{\text {st }}$ century drying. Various studies (e.g. Held et al., 2005; Biasutti et al., 2008; Lau et al., 2005) have shown a strong sensitivity of both the coupled and uncoupled versions of the GFDL models to SSTs, in the direction of strong Sahel drying in response to a uniform warming of the tropical oceans.

A previous version of the NCAR model was used by Haarsma et al. (2005) to project increasing future rainfall in the Sahel. They interpret the wet anomalies as the consequence of stronger monsoon winds, in turn a response to a strengthened land-sea temperature contrast and a deeper thermal Low. In an additional experiment, they showed that enhanced heating over the Sahara alone was sufficient to sustain this mechanism. In simulations of the Sahel, the NCAR model is also an outlier, because it does not link Sahel rainfall interannual variability to global SST (Biasutti et al., 2008). The MIROC model was singled out by Cook and Vizy (2006) as producing one of the best simulations of the twentieth-century climate in West Africa; their analysis shows that the future increase in Sahel rainfall is associated with a westerly flow enhancement, as it is true for observed positive fluctuations on shorter time scales (Grist and Nicholson, 2001).

\section{The Sahara Low: Forced Change}

We now explore how the CMIP3 models simulate the fundamental relationship between Sahel rainfall and monsoon circulation at the time scales of the forced climate 
change. As an index of the low-level circulation, we select the geopotential hight averaged over the Sahara (20N-30N, 10W-35E) minus the tropical mean hight at the same level. At low levels, this index well describes the strength of the Sahara Low.

The median 21C-20C anomaly in geopotential height over the Sahara minus the tropical mean average as a function of pressure levels and calendar month is displayed in Figure 4. During the winter half of the year, the anomalies are positive up to about $200 \mathrm{hPa}$ and are strongest at $400 \mathrm{hPa}$. During the summer months, the most prominent feature is the strengthened Sahara Low below about $700 \mathrm{hPa}$, with weak positive anomalies above.

A comparison of the vertical structure (below $250 \mathrm{hPa}$ ) of the $21 \mathrm{C}-20 \mathrm{C}$ change in Sahara geopotential height (Figure 4) to that of the 20C annual cycle (Figure 5) suggests a future strengthening and deepening of the climatological low-level Sahara Low during summertime, but a reduced baroclinicity in winter and fall. These features are consistent with our understanding of the mean Sahara Low as a thermal Low, driven by land-sea thermal contrast, and with enhanced warming of the land masses, which enhances the land-sea contrast in summer and reduces it in winter. Above about $250 \mathrm{hPa}$, the $21 \mathrm{C}-20 \mathrm{C}$ anomalies reinforce the existing annual cycle.

The 4 models that we are singling out for analysis agree with the median model in a qualitative way, but they differ greatly among themselves. This suggests that while an enhanced land-sea thermal contrast will generate a stronger Low in all models, the structure of the anomalous Low in the geopotential field may depend on more than the land-sea contrast in temperature, and may determine the sign of the associated Sahel rainfall anomalies. In the two "dry" models (Figure 6, left), the strengthening of the Sahara Low is limited both in intensity and in vertical extent; conversely the "wet" models (Figure 6, right) simulate much stronger negative anomalies in the lower half of the troposphere, with positive anomalies in the upper half to match. A horizontal 
view of the low-level geopotential height anomalies (Figure 7) shows that the "dry" models center the negative anomalies in the Arabic peninsula and simulate positive anomalies both in the Sahel and western Sahara and, more strongly, in Europe, while the "wet" models simulate a large-scale low that extends from the Sahara into Europe and western Asia. Cook and Vizy (2006) have noted that in the climatology of the GFDL models the surface thermal Low and mid-level Saharan High structure, along with its associated circulation features, is located too far to the east - and thus both GFDL models completely miss the southerly flow throughout the middle and lower troposphere north of $10 \mathrm{~N}$. It appears that the same limitation might influence the GFDL simulation of 21C-20C anomalies.

The relationship between more negative Sahara geopotential anomalies and more positive Sahel rainfall anomalies holds across all models of the CMIP3 dataset. Figure 8 shows the linear correspondence between trends in the Sahara Low (at 925hPa) and Sahel rainfall. We do not claim that the trend in the Sahara Low can by itself explain all inter-models variations in the Sahel rainfall trends; if that were the case one would expect that models that project negative Sahel rainfall anomalies would also project positive Sahara geopotential anomalies, which does not occur (at most, as seen for the GFDL models, the anomalies over the Sahara are split between a deepened Low to the east and an anomalous High to the west). The strength of the Low might be more relevant for models such as the NCAR CCSM3, that have weak connections between Sahel rainfall and SST (Biasutti et al., 2008), and less relevant for models with a stronger Sahel/SST connection, such as the GFDL models (Held et al., 2005; Biasutti et al., 2008). The correlation coefficient between projections of Sahel rainfall trends and projections of the strength of the Sahara Low is about 0.5; while this still leaves $75 \%$ of the inter-model variance in Sahel rainfall unexplained, it is a much stronger relationship than those with either SST or land-sea contrast (cfr. Figures 2 and 3 to Figure 8) and 
suggests that the Sahara might be a useful predictor of Sahel rainfall.

\section{The Sahara Low: Interannual variability}

An analysis of the $21 \mathrm{C}-20 \mathrm{C}$ anomalies can only describe the equilibrium situation, in which rainfall anomalies are consistent with circulation anomalies, but provides little insight on causality. To investigate the question of whether changes in the Sahara Low and monsoon circulation can be an independent source of anomalies in Sahel rainfall, we now turn to the dynamics of interannual variability in this region.

Figure 9 shows that the correlation between Sahel rainfall and the Sahara Low is significantly (at the $95 \%$ level) negative in nearly all of the CMIP3 models ${ }^{2}$, and remains negative in both the $20^{\text {th }}$ and $21^{\text {st }}$ century and independently of whether forced variability (with the centennial trend retained) or only internal variability (detrended time series) are present in the time series. The correlation between Sahel rainfall and the Sahara Low would imply that the basic dynamics of the annual cycle - whereby monsoon rainfall follows the development of the continental low-plays a role at these longer timescales. The robustness of this relationship suggests that we can indeed use the Sahel/Sahara relationship at interannual time scales as a model for interpreting the 21C-20C changes.

In the remainder of this section we describe the summertime Sahara/Sahel relationship at interannual time scales, in observations and the CMIP3 models, and show that the patterns of interannual anomalies are similar to the $21 \mathrm{C}-20 \mathrm{C}$ changes. We then analyze the Sahel/Sahara relationship at different lead and lag times, to show that variations in the Sahara Low are not just a consequence of Sahel rainfall (a Gill-like response to the associated latent heating; Gill, 1980), but can indeed force variations

\footnotetext{
${ }^{2}$ Note that geopotential data for the MIUB ECHO-G model were not available to us.
} 
in Sahel rainfall.

Figure 10a shows the observed correlation of the detrended Sahel rainfall index with the low-level $(925 \mathrm{hPa})$ geopotential and wind. The main feature of the rainfall/geopotential correlation is the dipole between the Pacific sector and the Atlantic-Indian sector; this pattern is essentially the Southern Oscillation pattern, as expected given the well established relationship between Sahel rainfall and El Niño Southern Oscillation (ENSO, e.g., Janicot et al., 2001). One feature that differentiates the correlation map of Figure 10a from the SOI pattern (besides the strength of the dipole) is the strong negative correlation of Sahel rainfall with geopotential height over the Sahara and over the northern tropical Atlantic, a feature that persists even if ENSO is regressed out of the time series (shown by the contour lines in Figure 10a). The pattern of correlation with the wind vectors confirms that - at interannual time scales, just as at the annual time scale - the monsoon rainfall depends on the development of the continental low: enhanced rainfall is linked to a cyclonic circulation around the Sahara and northern Tropical Atlantic with strong convergence into the Sahel.

The correlation between Sahel rainfall and the low level circulation in the CMIP3 models is depicted in Figures 10b,c which describe the ensemble-mean correlation and a measure of inter-model agreement. The latter (Figure 10c) was produced as follows: the correlation between the Sahel rainfall index and geopotential (or winds) was calculated for each model, and a value of one (negative one) was assigned at each gridpoint for which the simulated correlation was significantly positive (negative) at the $95 \%$ level. The ensemble mean and the agreement pattern are similar to the observed pattern of correlation. The models reproduce the observed relationship between Sahel rainfall and both the Southern Oscillation and the local Low over the Atlantic ITCZ and the Sahara.

We know that interannual-to-interdecadal variability in Sahel rainfall is driven by SST anomalies: El Niño, a negative Atlantic meridional gradient, and warming of the 
Indian Ocean have all been associated, in observations and models, to drought over the Sahel. Previous analysis has also shown that these relationships are replicated by the CMIP3 models (e.g., Lau et al., 2005; Biasutti et al., 2008). Therefore, the simulated pattern of correlation with the SOI pattern and with the tropical Atlantic is not surprising. There is one region where the models are at odds with observations: over India, China, and most of Indonesia, the models link positive Sahel rainfall anomalies to a low-level high, while the observations show the opposite sign relationship. This error is not corrected by regressing out the ENSO signal ${ }^{3}$.

The local correlation with the Sahara is a major feature of Figure 10b, as expected given that the Sahel/Sahara Low correlation is significant and negative for all but 3 models (Figure 9). Still, the pattern of the correlation can differ across models (not shown). For example, the "dry" models associate Sahel rainfall not as much with a proper Sahara Low as with two Lows, one over the eastern Sahara and the Mediterranean and one extending over the Atlantic - a splitting of the Sahara Low that is reminiscent of these models' positive and negative $21 \mathrm{C}-20 \mathrm{C}$ geopotential anomalies over the Sahara (see Figure 7, left). In contrast, the "wet" models associate increased Sahel rainfall with one, large-scale low pressure center extending over the entire northern Africa, again in a fashion consistent with the $21 \mathrm{C}-20 \mathrm{C}$ anomalies (Figure 7 , right).

We expect that rainfall anomalies can cause local circulation anomalies (e.g., Gill, 1980). As argued by Haarsma et al. (2005), the opposite may also be true: variability in the Sahara Low may be an independent source of variability in the Sahel. To make this case, we calculate the correlation between the Sahel rainfall index and the Sahara Low

\footnotetext{
${ }^{3}$ We have taken Nino3.4 as an ENSO index for the models as well, although model biases might make this a less than optimal choice to characterize ENSO in the CMIP3 models.
} 
at different lead and lag times and compare it with the auto-correlation of the Sahel Index itself. We do this both for observations (taking as an index of the Sahara Low the value of sea level pressure, instead of $925 \mathrm{hPa}$ geopotential hight, in order to have access to a century of data) and for the CMIP3 models. Figure 11 shows a summary of this analysis: for each panel the Sahel rainfall for a certain calendar month (June through October, spanning the rainy season) is taken as the base index for which lead and lag correlations with Sahel rainfall and Sahara Low are calculated. For observations, we show the correlations themselves, for the CMIP3 models, we plot both mean correlations and the number of models that produce significant positive or negative correlations (at the $95 \%$ level).

The patterns of lag-lead correlation in each single model (not shown) and, to some degree, in observations are noisier (that is, not as consistent from month to month) than those obtained by combining all models in the CMIP3 dataset, but overall both models and observations paint the same picture. The Sahel rainfall shows a memory of about one month (auto-correlations are significant in most models for one month lag or lead, but drop off for longer gaps). The instantaneous correlation between the Sahel and the Sahara indices is negative for all months, but is stronger during the core and the end of the rainy season (August through October). If such instantaneous correlation were just an indication of a response over the Sahara to anomalies in Sahel rainfall, we would expect the lagged correlations to mirror the auto-correlation of the Sahel index. Instead, the correlation between the Sahara and the Sahel is more often significant (and sometimes is maximum) when the Sahara leads by a month and, in most cases, it is negligible and even positive when the Sahara lags. We interpret this pattern of correlations as confirming that variability of the Sahara Low can be a driver of variability in Sahel rainfall.

The spatial pattern of the lead-lag correlation between the August Sahel rainfall 
index and the low-level geopotential is shown in Figure 12. The observed patterns are somewhat different if one uses the longer sea level pressure record (which might not be very accurate at the beginning of the record, especially in the interior of the Sahara desert) or uses the reanalyzed $925 \mathrm{hPa}$ geopotential height. Nevertheless, observations, reanalysis, and the CMIP3 models suggest a similar pattern of low-level circulation anomalies in response to Sahel rainfall anomalies. When the Sahel leads (Figure 12, top panels), the correlations over the Sahara are weakest (in the reanalysis) or positive (in observations and the models), while over the rest of the globe (not shown) the pattern does not change appreciably depending on the lead or lag, as one would expect if the remote correlations were mediated by the influence of SST, and would therefore present a certain amount of persistence. This indicates that Sahel rainfall anomalies can at most induce simultaneous circulation anomalies, but there is no feedback that would prolong the memory of such anomalies to the subsequent month. A comparison of the pattern of 0-lag correlation (Figure 12, middle panels) with that for the Sahel index lagging by a month (Figure 12, bottom panels) reveals the geopotential anomalies that are caused by contemporaneous Sahel rainfall anomalies. Both observations and the CMIP3 models indicate that positive Sahel rainfall anomalies intensify negative low-level geopotential height anomalies over western Sahara and the adjacent Atlantic ocean. Instead, the correlation between Sahel rainfall lagging and the Sahara Low leading is as strong as the 0-lag correlation, consistent with the Sahara Low being a source of variability for the Sahel and with the effect of Sahel rainfall anomalies being limited to the West.

The dynamical response to a precipitation anomaly in the Sahel can be understood partly using simple models such as the steady, linear shallow water equations on the equatorial beta plane subject to a localized mass source and Newtonian damping on the mass and velocity fields (Matsuno, 1966; Webster, 1972; Gill, 1980). Figure 13 shows the results of a calculation using this "Gill model", with an imposed heating 
whose dimensions are chosen to be very roughly representative of a strengthening or weakening of the mean Sahel rainfall. The model is the same as that used in Bretherton and Sobel (2003). ${ }^{4}$ As is standard, length is nondimensionalized by the equatorial deformation radius and time by that divided by the gravity wave speed. With that nondimensionalization, the heating (mass source) is

$$
\begin{array}{r}
M=\cos \left(\pi x /\left(2 s_{x}\right)\right) \exp \left(-\left(y-y_{0}\right)^{2} /\left(2 s_{y}^{2}\right)\right), \quad|x|<s_{x}, \\
M=0, \quad|x|>s_{x}
\end{array}
$$

where here $y_{0}=1, s_{y}=0.2$, and $s_{x}=1$. The nondimensional damping coefficient on both the momentum and mass equations is 0.15 . The domain is a channel, periodic in $x$ with length 20 and with rigid walls at $y= \pm 10$. The model is otherwise standard; further details are given in Bretherton and Sobel (2003).

Figure 13 shows that the response in the geopotential field to the meridionally narrow, off-equatorial heating is displaced to the northwest. The response is not very sensitive to the damping coefficient, which is the main free parameter in the calculation. Decreasing that coefficient causes the geopotential anomaly to spread further westward, while increasing it substantially is probably not realistic since the value 0.15 corresponds to a damping time of only a few days. The westward displacement is expected from Gill (1980) and other studies, but differs from the spatial relationship between Saharan geopotential anomalies and Sahel precipitation apparent in Figure 10, in which the Saharan geopotential anomalies lie directly to the north of the Sahel precipitation anomalies.

\footnotetext{
${ }^{4}$ It is not the version in which the weak temperature gradient approximation is made, but is equivalent to the original Gill (1980) model, except that the longwave approximation is not made.
} 
The above analysis of interannual variability suggests that positive rainfall anomalies in the Sahel can be driven by negative low-level geopotential anomalies in the Sahara, especially in eastern Sahara. We suggest that what holds at interannual time scales also holds at the time scale of the forced trend. If a sufficiently strong, large scale Low over the Sahara were to occur in response to $21^{\text {st }}$ century forcings, it might be strong enough to counteract the effect of the SST warming, leading to a net increase in Sahel rainfall. In order to be able to understand the ultimate source of the discrepancy in the CMIP3 projections of Sahel rainfall, we need to close the circle and understand what can cause different simulations of the Sahara Low. This is the focus of our current research.

\section{Summary and Conclusions}

The subject of this study is the relationship between summer rainfall in the Sahel and the low-level geopotential Low over the Sahara. We suggest that variations in the Sahara Low can force rainfall anomalies at timescales from annual to centennial, and therefore that the sources of climate change in the Sahara should be considered alongside changes in SST in order to understand the origin of discrepant projections for $21^{\text {st }}$ century Sahel rainfall in the CMIP3 data set.

We have shown that inter-model variations in the 21C-20C Sahara Low anomalies correspond to those in Sahel rainfall: models that do not simulate a strong Low (even in the presence of strong land/sea temperature contrast) project strong drying, while models that simulate a Low that extends over the Mediterranean and the middle East project wetting (Section 2). The fact that there is a correspondence between changes in Sahel rainfall and the Sahara Low, as defined by geopotential, while no such correspondence can be found with the land-sea thermal contrast, indicates that the details of the anomalous Low (its vertical depth and its horizontal extent) are, on 
one hand, important for the Sahel and, on the other hand, not fully determined by the land-sea thermal contrast.

The lead-lag relationship between Sahara and Sahel at interannual time scales indicates that the Sahara Low can force interannual variability in the Sahel with a lead time of one month. This behavior of the CMIP3 models is consistent with observations (see our analysis in Section 3 and a recent study by Nicholson and Webster, 2007).

In the annual cycle, the driver of the Sahara Low is obviously solar radiation, both directly over the Sahara and through its influence on the surrounding SST (Biasutti et al., 2003). At interannual timescales, we expect the proximate sources of variability to be internal atmospheric dynamics and tropical SST. What drives changes in the Sahara Low at the timescale of the trend? A definite answer to this question is outside the scope of this study, yet we can postulate that all that affects the Sahara Low at shorter time scales might affect its trend. First, as in the annual cycle, a direct radiative forcing, in this case from both greenhouse gases and aerosols, possibly modified by local land-atmosphere feedbacks. Second, as suggested by a preliminary analysis of interannual variability, changes in the tropical SST and in the mid-latitude jet.

Previous studies have focused on the role of SST trends in forcing rainfall trends in the Sahel. We have shown that the Sahara Low is a skillful predictor for Sahel rainfall changes, and that land-sea thermal contrast alone does not control those characteristics of the Low important for the Sahel. We suggest that direct radiative influences and mid-latitude influences on the Sahara Low must also be explored, alongside the role of SST, if we want to explain the disparate projections for Sahel rainfall in the CMIP3 models' simulations of the $21^{\text {st }}$ century.

Acknowledgments. The authors gratefully acknowledge support from NOAA (grants NA03OAR4320179, NA06OAR4310143) and the NSF ADVANCE program at the Earth Institute at Columbia University. 


\section{REFERENCES}

Allan, R. J. and T. J. Ansell, 2006: A new globally complete monthly historical mean sea level pressure data set (HadSLP2): 1850-2004. J. Climate, 19, 5816-5842.

Bader, J. and M. Latif, 2003: The impact of decadal-scale Indian Ocean sea surface temperature anomalies on Sahelian rainfall and the North Atlantic Oscillation. Geophys. Res. Lett., 30(22), 2169.

Biasutti, M., D. S. Battisti and E. S. Sarachik, 2003: The annual cycle over the tropical Atlantic, South America, and Africa. J. Climate, 16, 2491-2508.

Biasutti, M. and A. Giannini, 2006: Robust Sahel drying in response to late 20th century forcings. Geophys. Res. Lett., 33, L11706.

Biasutti, M., I. M. Held, A. H. Sobel and A. Giannini, 2008: SST forcings and Sahel rainfall variability in simulations of the twentieth and twenty-first centuries. Journal of Climate, 21(14), 3471-3486.

Bretherton, C. S. and A. H. Sobel, 2003: The Gill model and the weak temperature gradient approximation. Journal of Atmospheric Sciences, 60, 451-460.

Christensen, J., B. Hewitson, A. Busuioc, A. Chen, X. Gao, I. Held, R. Jones, R. Kolli, W.-T. Kwon, R. Laprise, V. M. Rueda, L. Mearns, C. Menéndez, J. Räisänen, A. Rinke, A. Sarr and P. Whetton, 2007: Climate Change 200\%: The Physical Science Basis. Contribution of Working Group I to the Fourth Assessment Report of the Intergovernmental Panel on Climate Change. Chap. Regional Climate Projections. Cambridge University Press, Cambridge, United Kingdom and New York, NY, USA.

Cook, K., 2008: Climate science: The mysteries of Sahel droughts. Nature Geoscience, 1, 647 -648 .

Cook, K. and E. K. Vizy, 2006: Coupled model simulations of the West African monsoon system: 20th and 21st century simulations. J. Climate, 19(15), 3681-3703. 
Eltahir, E. A. B. and C. Gong, 1996: Dynamics of wet and dry years in West Africa. J. Climate, 9, 1030-1042.

Emanuel, K. A., 1995: On thermally direct circulations in moist atmospheres. J. Atmos. Sci., 52, 1529-1534.

Giannini, A., M. Biasutti, A. H. Sobel and I. M. Held, 2008: A global perspective on African climate. Climatic Change.

Gill, A. E., 1980: Some simple solutions for heat-induced tropical circulation. Q. J. R. Meteorol. Soc., 106, 447-462.

Gleckler, P., K. Taylor and C. Doutriaux, 2008: Performance metrics for climate models. J. Geophys. Res, 113.

Grist, J. P. and S. E. Nicholson, 2001: A study of the dynamic factors influencing the rainfall variability in the West African Sahel. J. Climate, 14, 1337-1359.

Haarsma, R. J., F. M. Selten, S. L. Weber and M. Kliphuis, 2005: Sahel rainfall variability and response to greenhouse warming. Geophys. Res. Lett., 32, L17702.

Held, I. M., T. L. Delworth, J. Lu, K. L. Findell and T. R. Knutson, 2005: Simulation of Sahel drought in the 20th and 21st centuries. Proc. Natl. Acad. Sci., 102(50), 17891-17896.

Herceg, D., A. Sobel and L. Sun, 2007: Regional modeling of decadal rainfall variability over the Sahel. Clim. Dyn., 29(1), 89-99.

Hoerling, M., J. Hurrell, J. Eischeid and A. Phillips, 2006: Detection and attribution of 20th century northern and southern African rainfall change. J. Climate, 19(16), 3989-4008.

Houghton, J., L. Meira Filho, B. Callender, N. Harris, A. Kattenberg, K. Maskell and Eds., 1995: Climate change 1995: the science of climate change. p. 572pp., Contribution of Working Group I to the Second Assessment of the Intergovernmental Panel on Climate Change. Cambridge University Press.

Hulme, M., 1992: A 1951-80 global land precipitation climatology for the evaluation of general circulation models. Climate Dyn., 7, 57-72. 
Janicot, S., S. Trzaska and I. Poccard, 2001: Summer Sahel-ENSO teleconnection and decadal time scale SST variations. Clim. Dyn., 18, 303-320.

Kalnay, E., M. Kanamitsu, R. Kistler, W. Collins, D. Deaven, L. Gandin, M. Iredell, S. Saha, G. White, J. Woollen, Y. Zhu, M. Chelliah, W. Ebisuzaki, W. Higgins, J. Janowiak, K. Mo, C. Ropelewski, J. Wang, A.Leetmaa, R. Reynolds, R. Jenne and D. Joseph, 1996: The NCEP/NCAR 40-year reanalysis project. Bull. Amer. Meteor. Soc., 77, $437-471$.

Kaplan, A., M. Cane, Y. Kushnir, A. Clement, M. Blumenthal and B. Rajagopalan, 1998: Analyses of global sea surface temperature 1856-1991. J. Geophys. Res., 103, $18,567-18,589$.

Lau, K. M., S. S. P. Shen, K.-M. Kim, and H. Wang, 2005: A multimodel study of the twentieth-century simulations of Sahel drought from the 1970s to 1990s. J. Geophys. Res., 111(D07111).

Matsuno, T., 1966: Quasi-geostrophic motions in the equatorial area. J. Meteor. Soc. Japan, 44(1), 25-43.

Meehl, G., C. Covey, T. Delworth, M. Latif, B. McAvaney, J. Mitchell, R. Stouffer and K. Taylor, 2007a: The WCRP CMIP3 Multimodel Dataset: A New Era in Climate Change Research. Bull. Amer. Meteor. Soc., 88(9), 1383-1394.

Meehl, G., T. Stocker, W. Collins, P. Friedlingstein, A. Gaye, J. Gregory, A. Kitoh, R. Knutti, J. Murphy, A. Noda, S. Raper, I. Watterson, A. Weaver and Z.-C. Zhao, 2007b: Climate Change 200\%: The Physical Science Basis. Contribution of Working Group I to the Fourth Assessment Report of the Intergovernmental Panel on Climate Change. Chap. Global Climate Projections. Cambridge University Press, Cambridge, United Kingdom and New York, NY, USA.

Neelin, J. D., M. Munnich, H. Su, J. Meyerson and C. Holloway, 2006: Tropical drying trends in global warming models and observations. Proc. Natl. Acad. Sci., 103, $6110-6115$. 
Nicholson, S. and P. Webster, 2007: A physical basis for the interannual variability of rainfall in the Sahel. Q. J. R. Meteorol. Soc., 133(629), 2065 - 2084.

Reichler, T. and J. Kim, 2008: How well do coupled models simulate today's climate? Bull. Amer. Meteor. Soc., 89, 303-311.

Sutton, R. T., B. Dong and J. M. Gregory, 2007: Land/sea warming ratio in response to climate change: IPCC AR4 model results and comparison with observations. Geophys. Res. Lett., 34(L02701).

Webster, P., 1972: Response of the tropical atmosphere to local, steady forcing. Monthly Weather Review, 100(7), 518-541.

Webster, P. J., 1987: Monsoons. Chap. The Elementary Monsoon, pp. 3-32. J. Wiley Co.

This manuscript was prepared with AGU's ${ }^{A} T_{\mathrm{EX}}$ macros v3.0, with the extension package 'AGU'+' by P. W. Daly, version ? from ?. 


\section{Figure Captions}
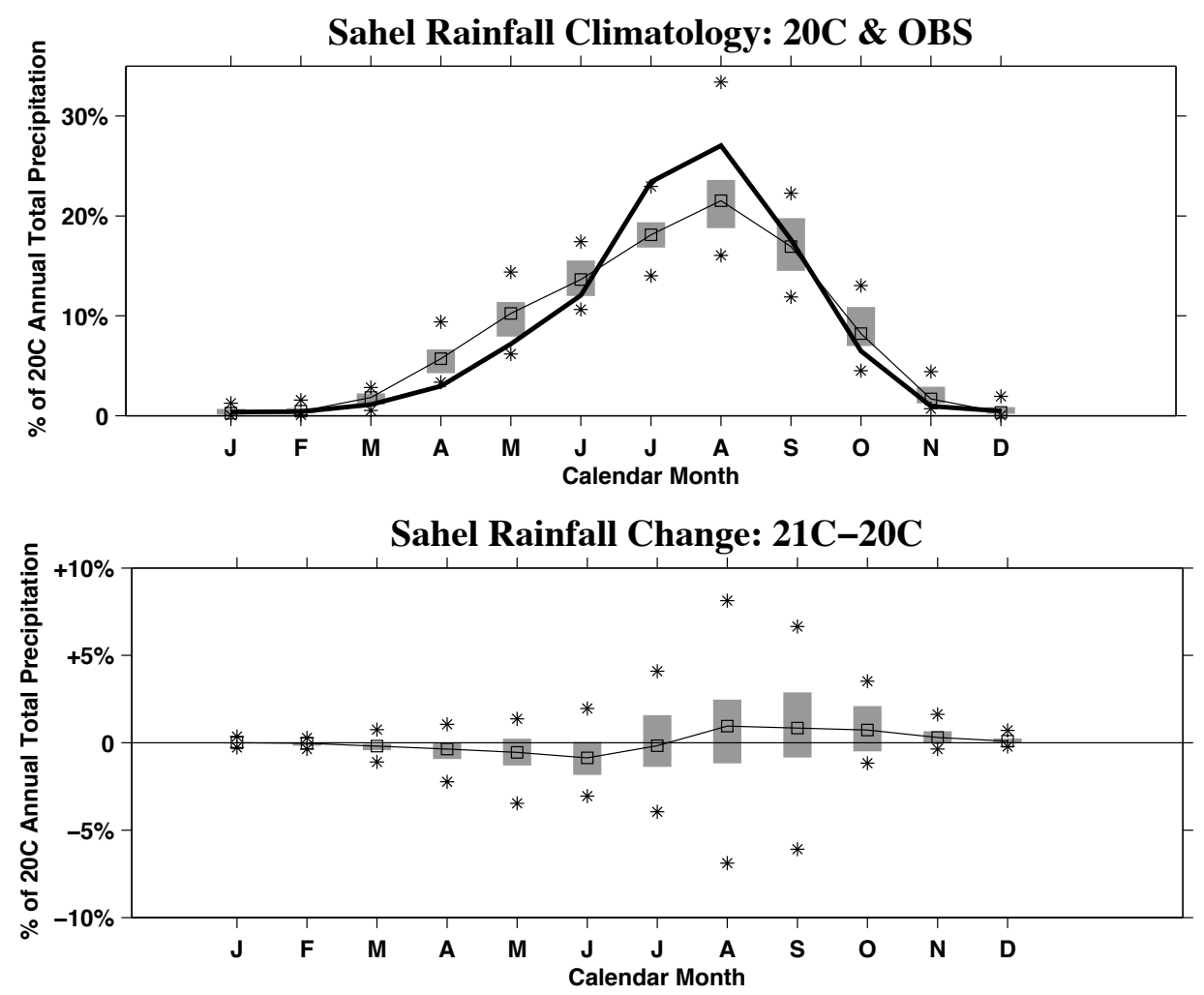

Figure 1. CMIP3 simulations of (top) 20C Sahel rainfall and (bottom) 21C-20C Sahel rainfall change (\% of total annual rainfall) as a function of calendar month. The solid line and open squares show the mean anomaly, the grey vertical bars represent the 25 th and 75 th percentile, and the stars are the maximum and minimum values. The thick black line in the upper panel is observations (Hulme, 1992) for 1975-1998. 

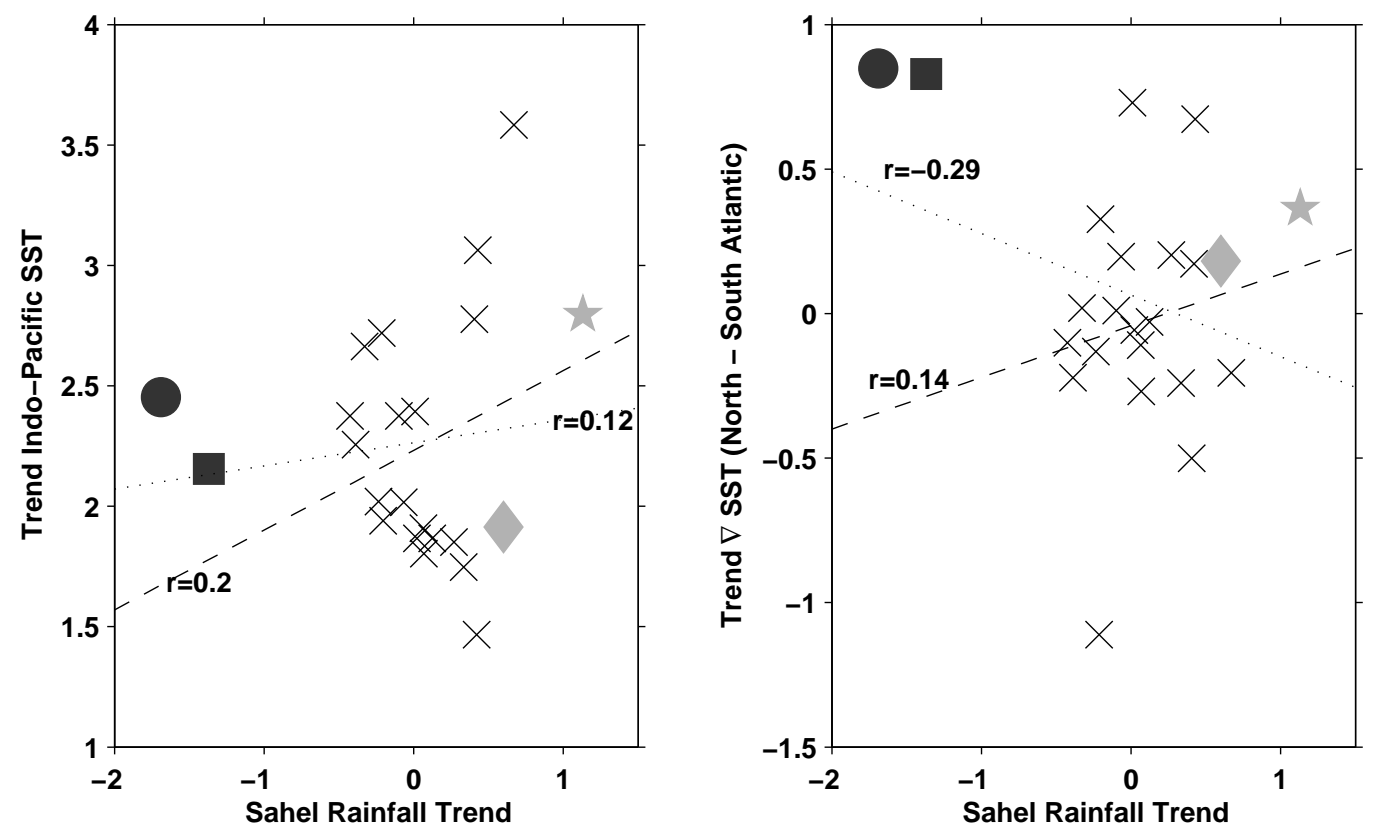

Figure 2. CMIP3 simulations of $21 \mathrm{C}$ trend in summer (July-August-September, JAS) Sahel rainfall $\left(\mathrm{mm}\right.$ day $^{-1}$ per century) and in (left) tropical Indo-Pacific SST $\left(20^{\circ} \mathrm{S}-20^{\circ} \mathrm{N} ; 50{ }^{\circ} \mathrm{E}-\right.$ $90^{\circ} \mathrm{W}$; units of ${ }^{\circ} \mathrm{C}$ per century) and (right) bulk cross-equatorial meridional gradient in tropical Atlantic SST [north $\left(7^{\circ} \mathrm{N}-30^{\circ} \mathrm{N} ; 70^{\circ} \mathrm{W}-20^{\circ} \mathrm{W}\right)$ minus south $\left(20^{\circ} \mathrm{S}-7^{\circ} \mathrm{N} ; 40^{\circ} \mathrm{W}-5^{\circ} \mathrm{E}\right)$; units of ${ }^{\circ} \mathrm{C}$ per century]. The best linear fit lines are calculated using all data (dotted) or excluding four models with extreme anomalies (dashed). The four models are the GFDL CM2.0 (circle) and 2.1 (square), MIROC MEDRES (star) and NCAR CCSM3 (diamond). 

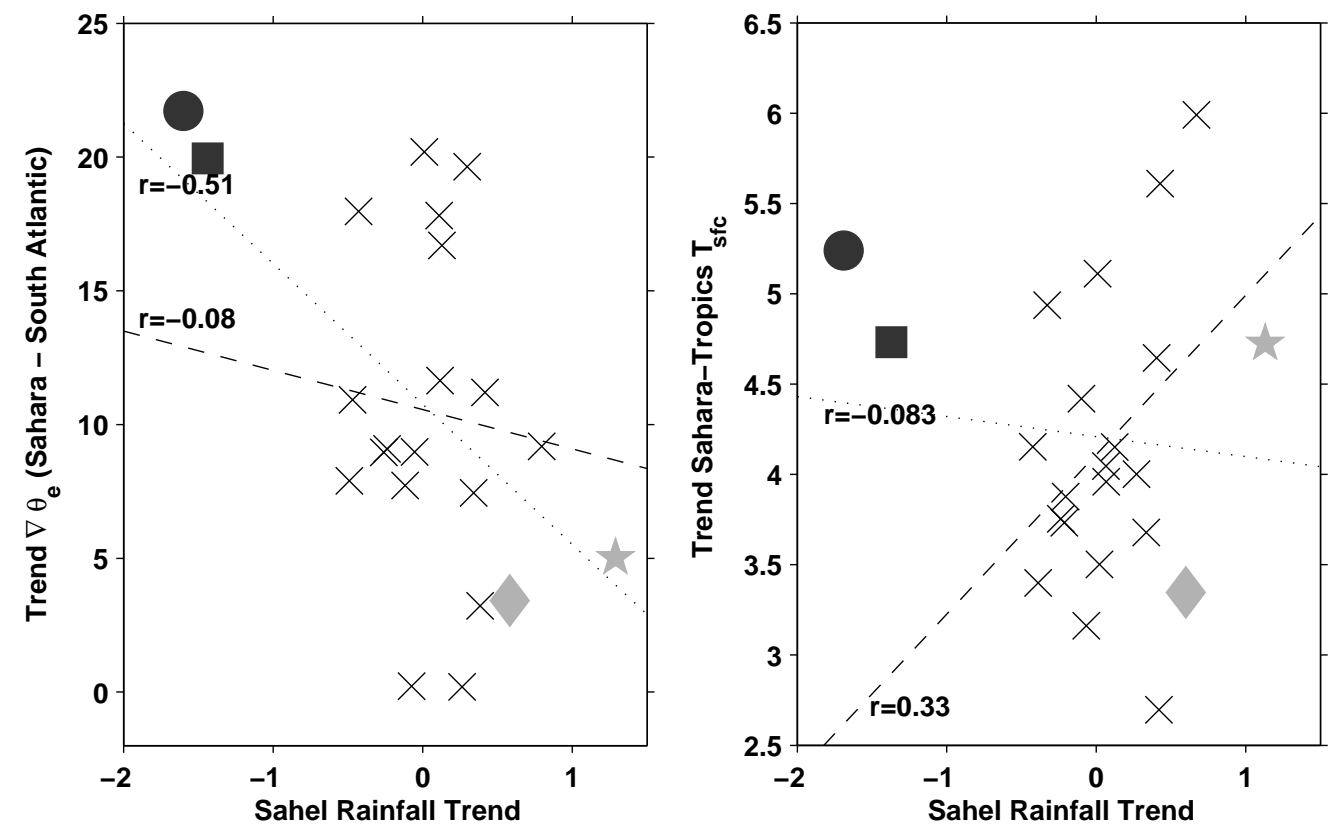

Figure 3. CMIP3 simulations of $21 \mathrm{C}$ trend in summer (July-August-September, JAS) Sahel rainfall ( $\mathrm{mm} \mathrm{day}^{-1}$ per century) and in (left) bulk meridional gradient in surface equivalent potential energy (K per century) between the Sahara (20N-30N, 20W-35W) and South Tropical Atlantic (20S-Eq., 30W-10E) and (right) surface air temperature $\left({ }^{\circ} \mathrm{C}\right.$ per century) over the Sahara minus the tropical average (30S-30N). The best linear fit lines are calculated using all data (dotted) or excluding four models with extreme anomalies (dashed). The four models are the GFDL CM2.0 (circle) and 2.1 (square), MIROC MEDRES (star) and NCAR CCSM3 (diamond). 


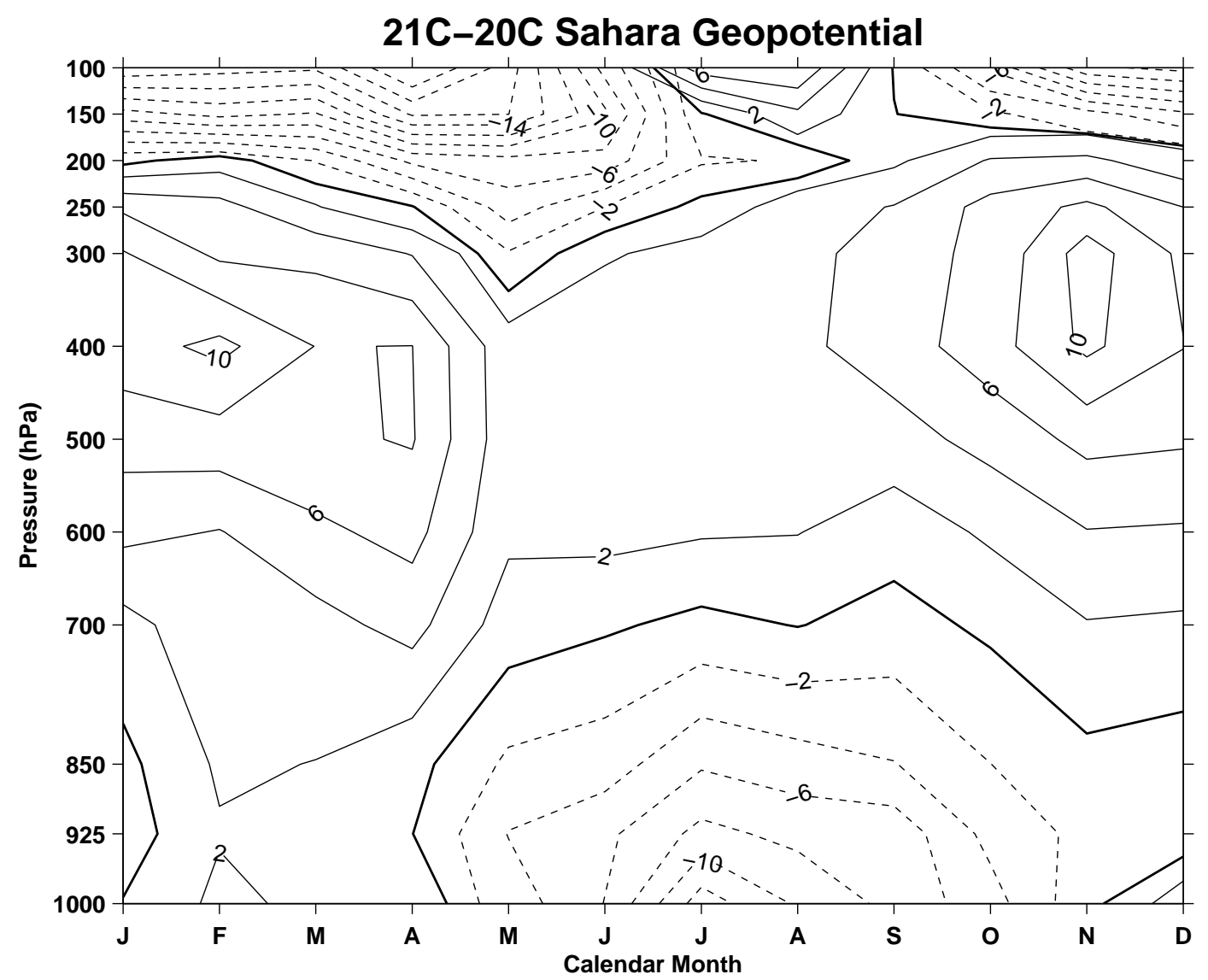

Figure 4. Median 21C-20C difference in Sahara (20N-30N, 10W-35E) mean minus tropical (30S-30N) mean geopotential height, as a function of calendar month and pressure level. 


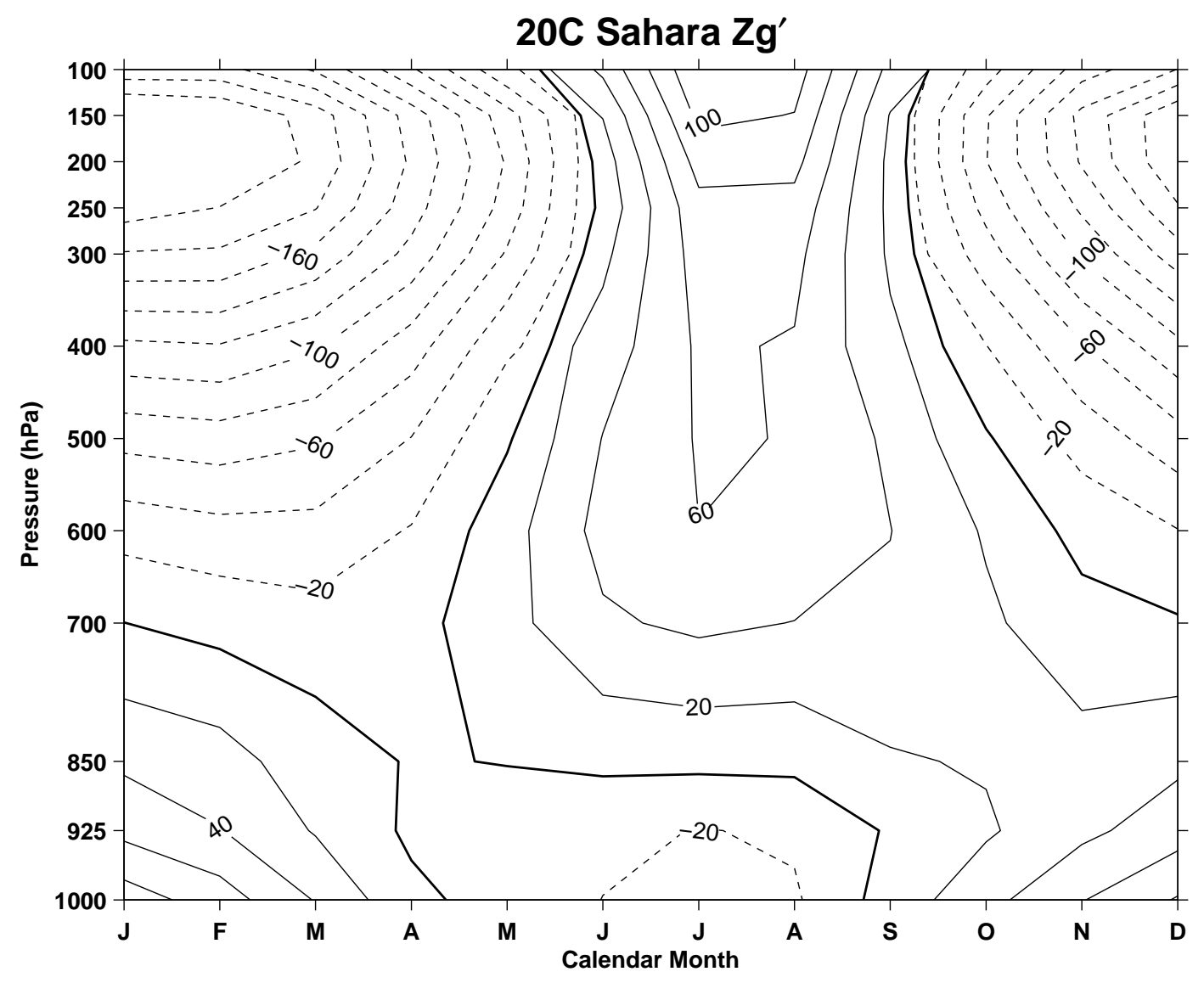

Figure 5. Median annual cycle of 20C Sahara (20N-30N, 10W-35E) mean minus tropical (30S-30N) mean geopotential height, as a function of calendar month and pressure level. 

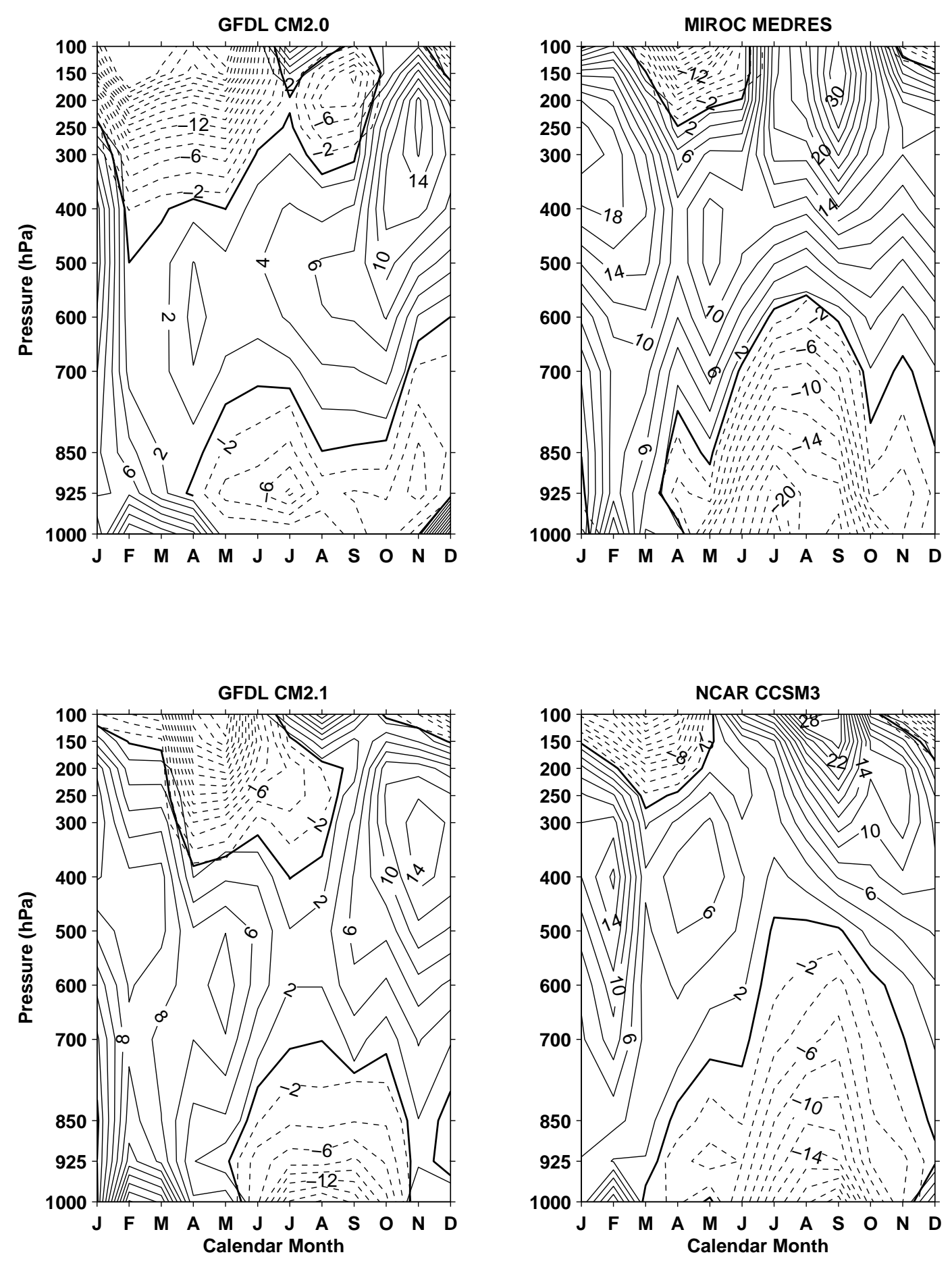

Figure 6. $21 \mathrm{C}-20 \mathrm{C}$ difference in Sahara (20N-30N, 10W-35E) mean minus tropical (30S-30N) mean geopotential height, as a function of calendar month and pressure level in "dry" models (left) and "wet" models (right). 
GFDL CM2.0
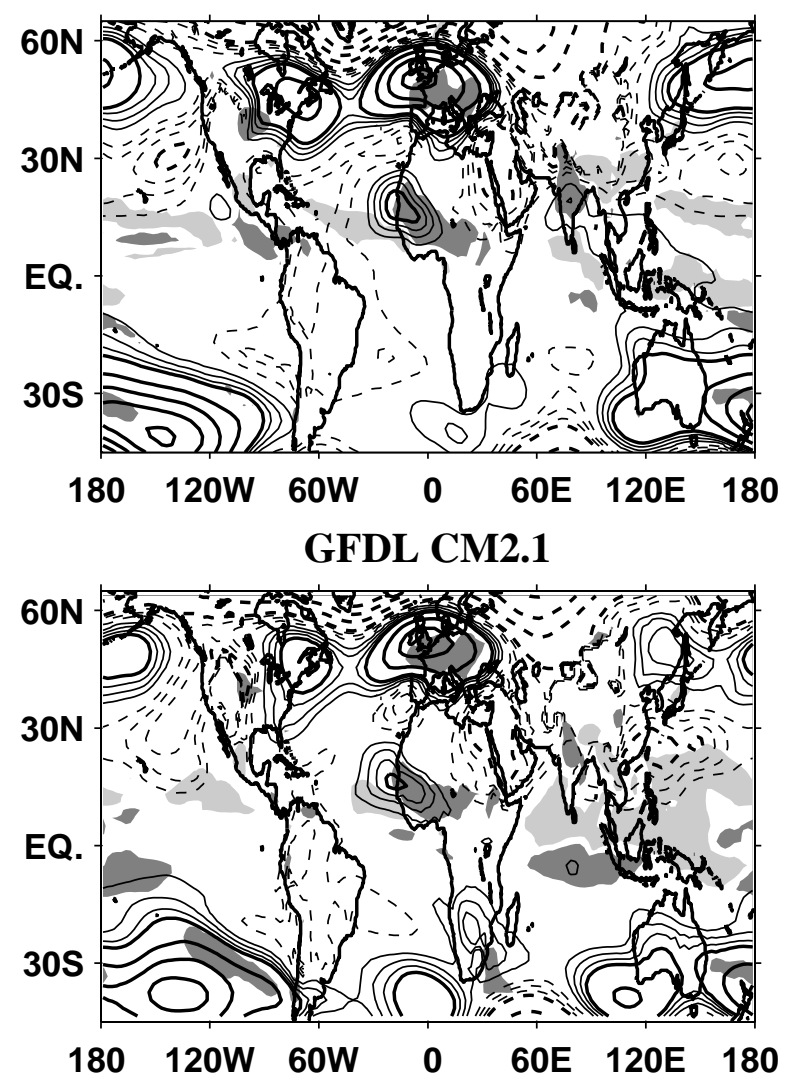

MIROC MEDRES
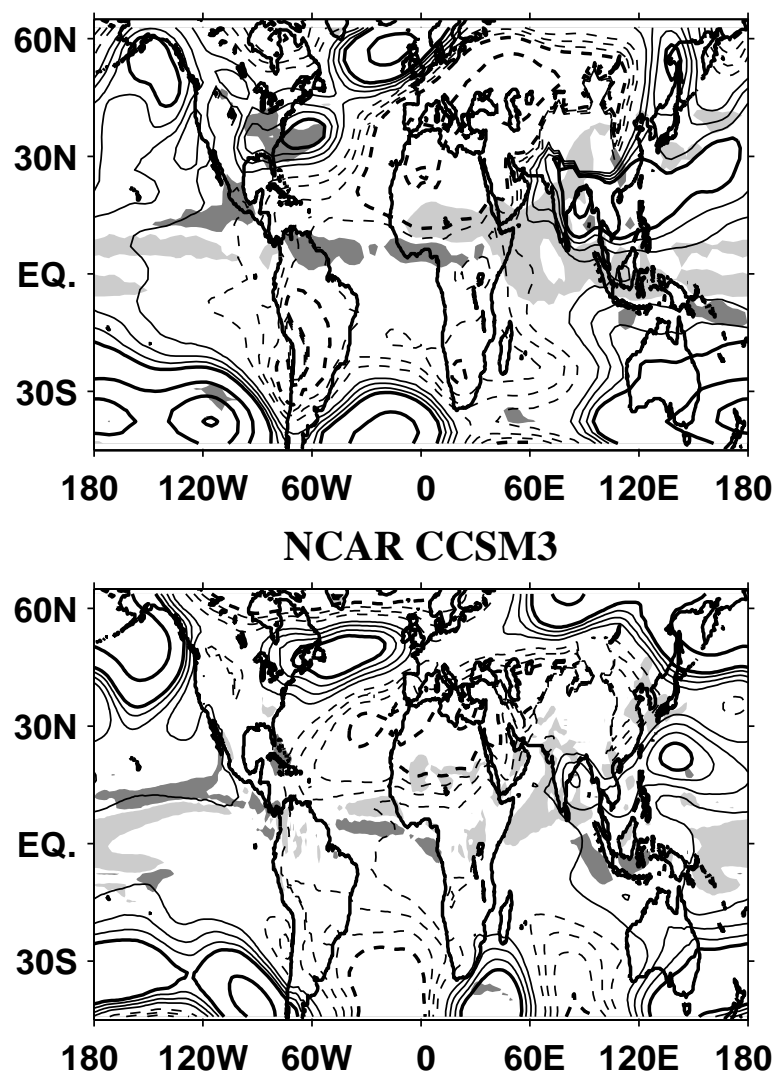

Figure 7. 21C-20C difference in July-August-September $850 \mathrm{hPa}$ geopotential height with the tropical mean removed (light lines are $\pm 2, \pm 4, \pm 6$, thick lines have a contour interval of $8 \mathrm{~m}$ ) and precipitation [light (dark) shading denotes anomalies greater than positive (negative) $1 \mathrm{~mm} /$ day]. 


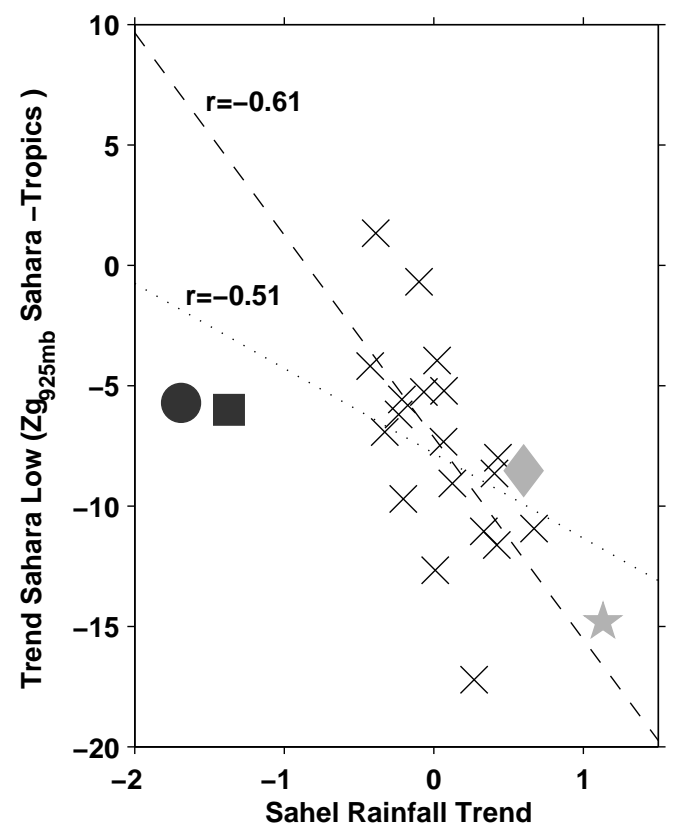

Figure 8. CMIP3 simulations of 21C trend in summer (July-August-September, JAS) Sahel rainfall ( $\mathrm{mm}$ day $^{-1}$ per century) and in the difference in $925 \mathrm{hPa}$ geopotential height (meters per century) between the Sahara (20N-30N, 20W-35W) and the tropical band (30S-30N). The best linear fit lines are calculated using all data (dotted) or excluding four models with extreme anomalies (dashed). The four models are the GFDL CM2.0 (circle) and 2.1 (square), MIROC medres (star) and NCAR CCSM3 (diamond). 
20C: (SRI,Low)

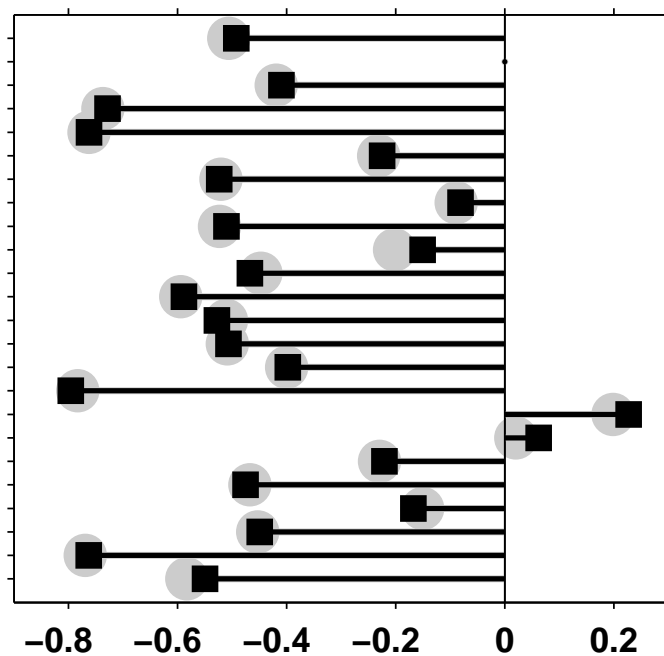

21C: (SRI,Low)

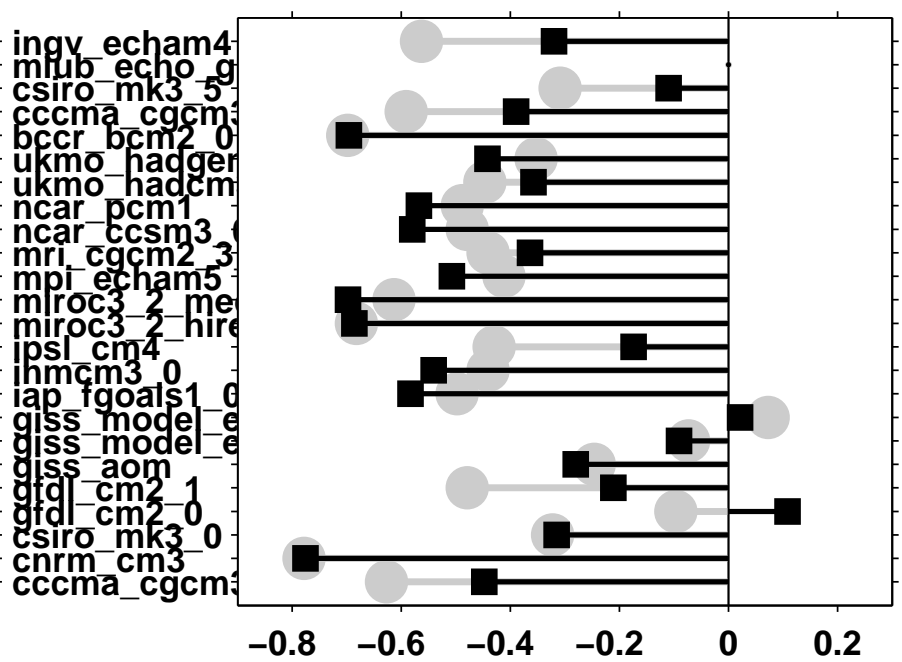

Figure 9. Correlation between the Sahel Rainfall Index (JAS rainfall averaged over the area between $10 \mathrm{~N}-20 \mathrm{~N}$ and $20 \mathrm{~W}-40 \mathrm{E}$ ) and the Sahara Low Index (the difference between Sahara average (20N-30N; $10 \mathrm{~W}-30 \mathrm{~W})$ and tropical average (30S-30N) geopotential at 925hPa) in (left) 20C and (right) 21C. Circles indicate correlations between detrended time series, squares between unfiltered time series. Interannual correlations above \pm 0.16 are significant at the 95\% level. 


\section{OBSERVATIONS}

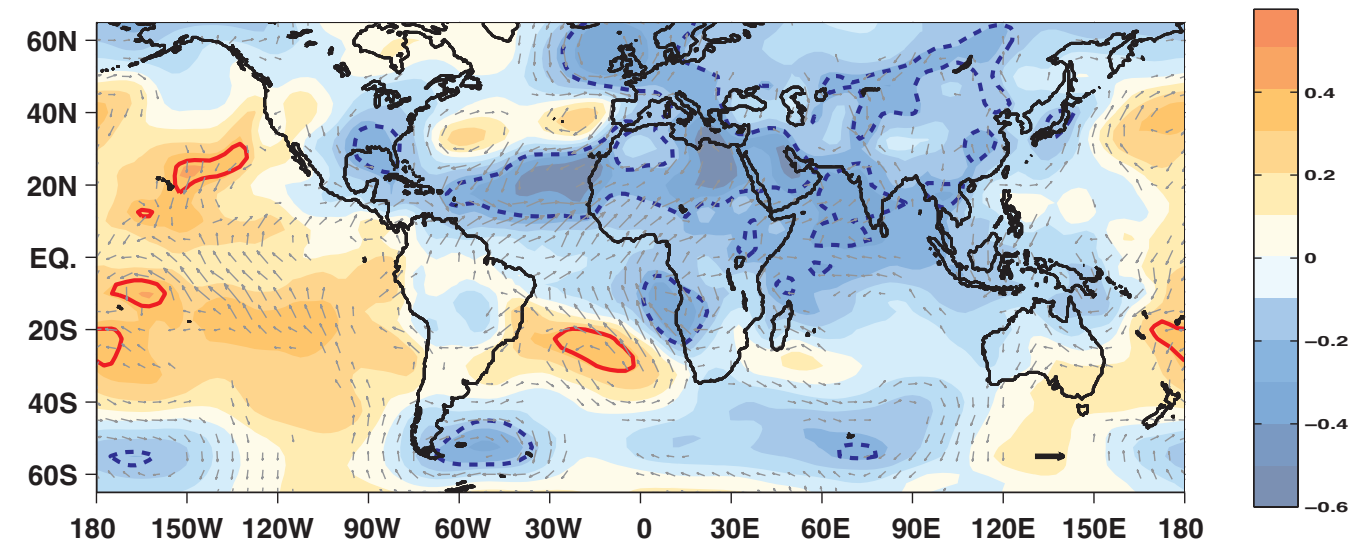

CMIP3 MODELS MEAN

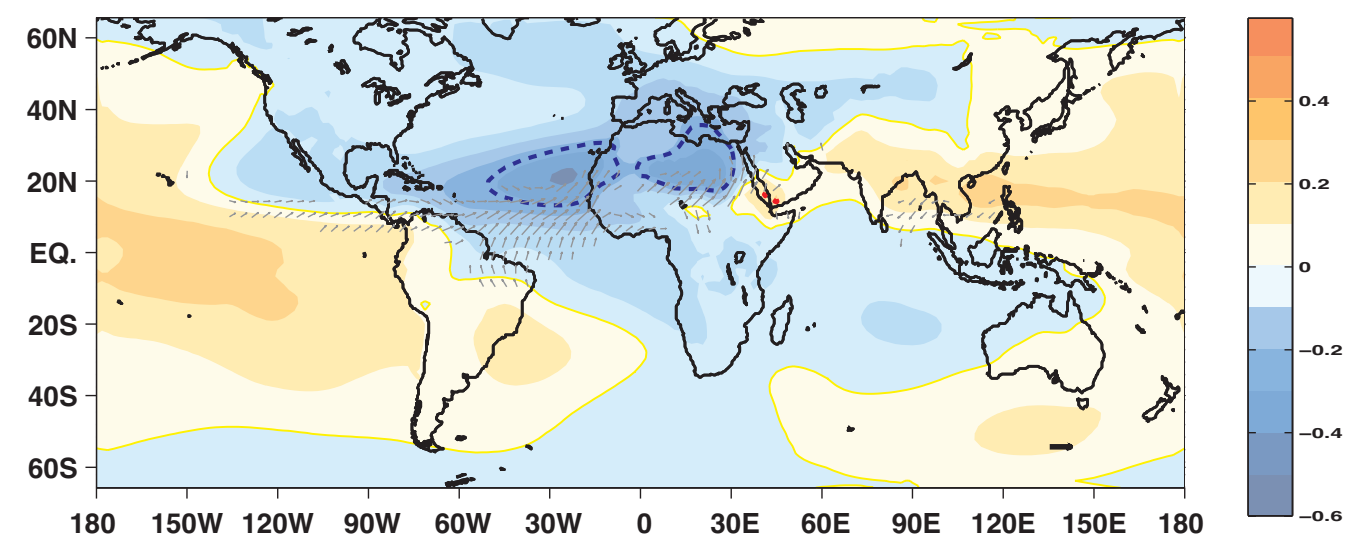

CMIP3 MODELS SIGNIFICANCE

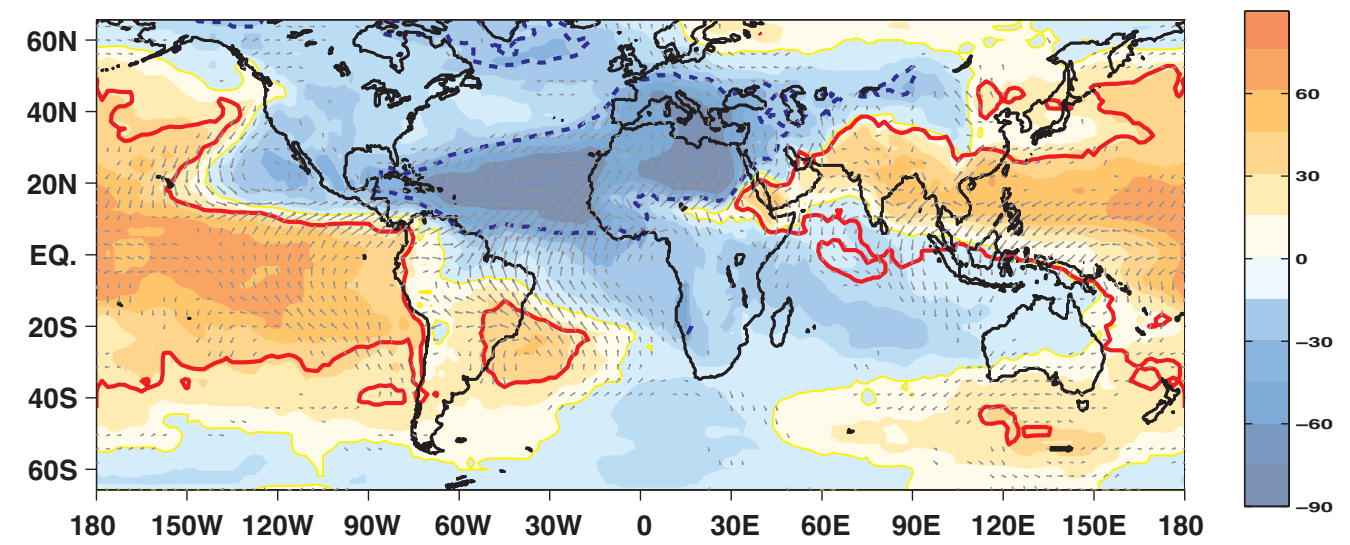

Figure 10. (Top.) Observed correlation between detrended Sahel Index and 925hPa geopotential height (shading interval is 0.1) and winds (westerly and southerly directions indicate positive correlations; only vectors for which at least one component is larger than 0.2 are plotted; the unit vector is plotted in the lower right corner). The thick solid (dashed) contour indicates the $0.3(-0.3)$ correlation level with a time series of $925 \mathrm{hPa}$ geopotential from which the variability associated with ENSO has been removed. Correlations above \pm 0.21 are significant at the $95 \%$ level. (Center.) As in (Top.), but for the CMIP3 mean correlation. (Bottom) Number of models with significant correlation between the detrended Sahel Index 

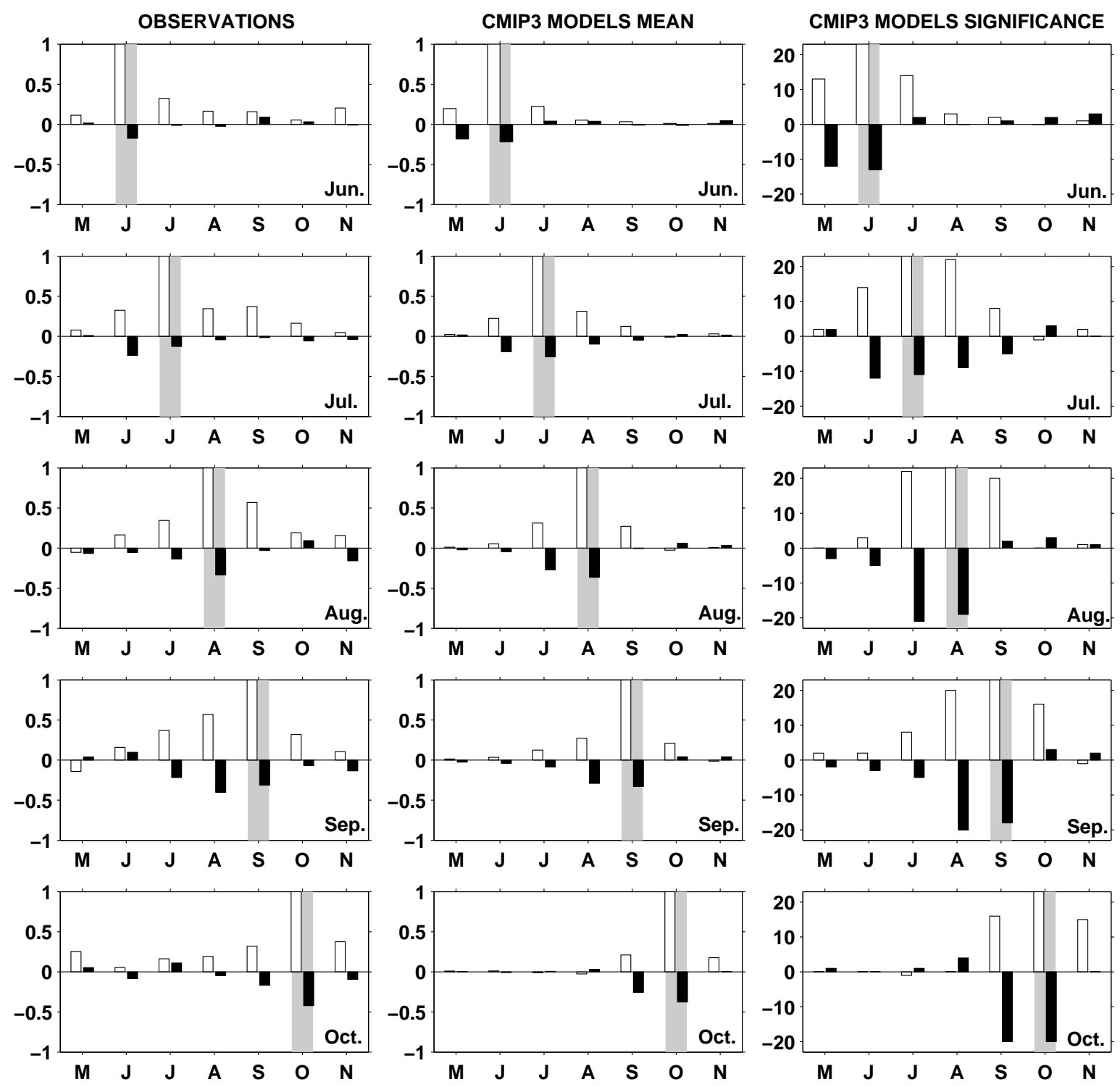

Figure 11. (Left) Observed correlation between detrended Sahel rainfall and sea level pressure over 1900-1998 (Center) Mean CMIP3 correlation and (Right) number of models with significant correlation between the $21 \mathrm{C}$ detrended monthly Sahel Index and (open, left bars) itself or (filled, right bars) the Sahara 925hPa geopotential height. In each panel the Sahel index is taken for a different calendar month (June through October, from top to bottom), and the correlations at 0-lag are marked by a grey background. 

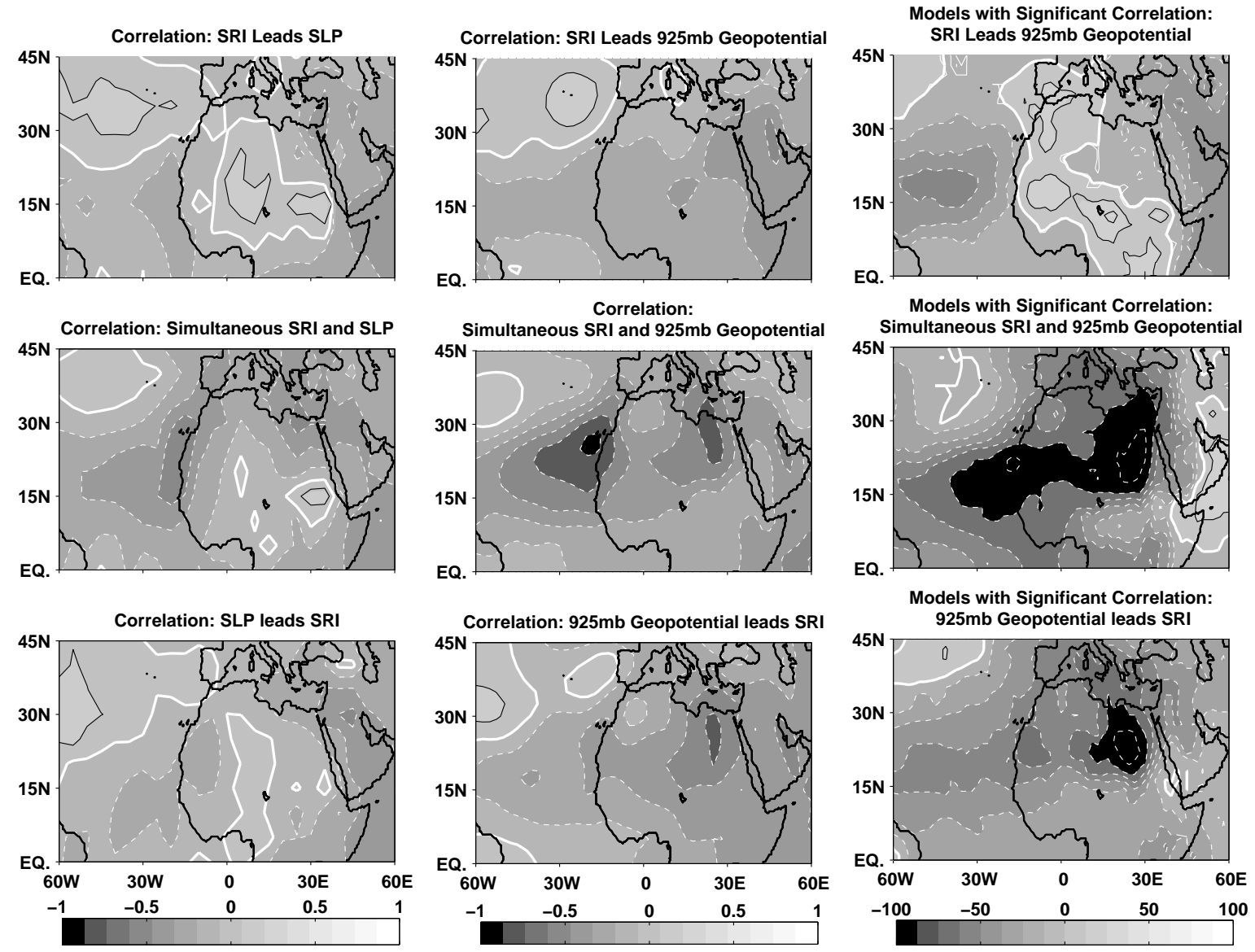

Figure 12. (Left) Observed correlation between detrended August Sahel rainfall and sea level pressure over 1900-1998; (center) correlation of observed Sahel rainfall and the 925hPa geopotential height; (right) number of models (expressed as percentage) with significant (95\% level) correlation between the $21 \mathrm{C}$ detrended August Sahel Index and 925hPa geopotential height. In the top panels the Sahel index leads (and the geopotential lags) by a month; the middle panels show the 0-lag correlations; the bottom panels show Sahel rainfall lagging by a month. Dark (light) grays and dashed white (solid black) contours indicate negative (positive) correlations, the shading interval is 0.15 for observations and $15 \%$ for the models; the zero line is the thick white contour. 


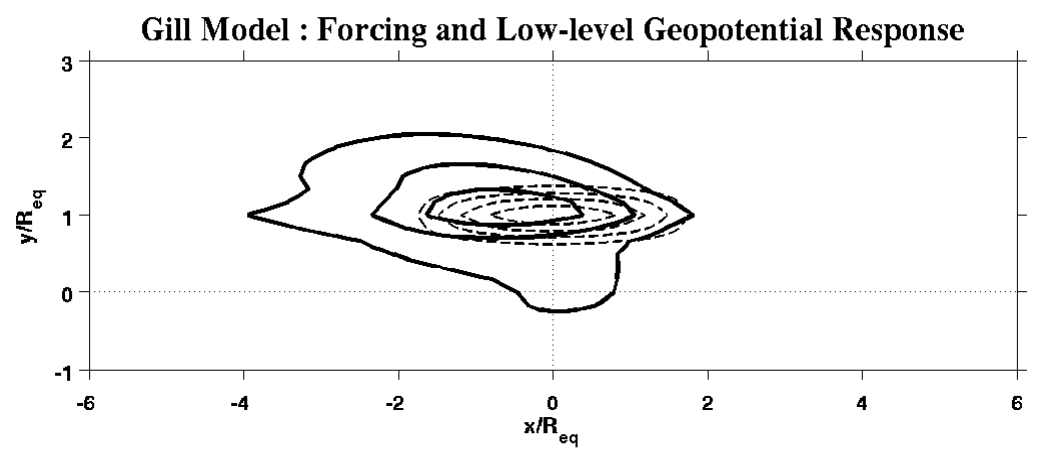

Figure 13. The low-level geopotential response (thick solid line) to a negative heating forcing (thin dashed line) in a Gill-like model (see text for details). 